\title{
Code of Conduct for Case Study Reporting and Publication
}

\author{
Viroj Wiwanitkit M.D. \\ Visiting Professor Hainan Medical University, China \\ Honorary Professor Dr. DY Patil University, India \\ wviroj@yahoo.com
}

The case study is a common and useful type of medical publication. It usually reports the new observation, intervention or rare forgotten findings [1]. It can be a useful resource for many situations such as emergence of outbreak [2]. To report a case study, the reporter has to follow standard ethical practice. In fact in any "international case study and case report journal", the code of conduct is usually an important concern and requirement. Here, the examples of important code of conduct quoted can be directly assessed from referencing journal http://case-study-case-report.simdif.com. With a reference to standard code of conduct, it is expected that all authors have to follow and practice in the correct and ethical way. In brief, these three things have to be strictly considered and followed:a) conflict of interest clearance and declaration, b) and c) inform consent clearance, c) human and animal rights protection and d) clearance for free of plagiarism, duplication and misconduct [3].Failure for following of the code of conduct usually results in ethical problem, rejection of submitted paper, retraction of the published article or sanctioning by international society [3]. When one start to write a case study for publication, one should concern on the mentioned code of conduct and prepare the manuscript according to the instruction of author. One might expect for an acceptance of article for publication and a good published article can be further worldwide referenced!

\section{REFERENCES}

1. Wiwanitkit V. CASE REPORT: what, why and how to report? Case Study Case Rep. 2012; 2(1): 1-3

2. Wiwanitkit V. The usefulness of case reports in managing emerging infectious disease. J Med Case Rep. 2011 May 20;5:194. doi: 10.1186/1752-1947-5-194.

3. Case Study and Case Report. GUIDE FOR AUTHORS. Available online at http://case-study-case-report. simdif.com/guide-for-authors.html

Citation: Viroj Wiwanitkit M.D. "Code of conduct for case study reporting and publication ". American Research Journal of Clinical Case Reports; 1(1): 1-1.

Copyright (C) Viroj Wiwanitkit M.D. This is an open access article distributed under the Creative Commons Attribution License, which permits unrestricted use, distribution, and reproduction in any medium, provided the original work is properly cited. 